\title{
Pectin Rhamnogalacturonan II: On the "Small Stem with Four Branches" in the Primary Cell Walls of Plants
}

\author{
Beda M. Yapo ${ }^{1,2}$ \\ ${ }^{1}$ Unit of Training and Research in Food Science and Technology (UFR-STA), University of Abobo-Adjamé (UAA), \\ 22 BP 759 Abidjan 22, Cote D'Ivoire \\ ${ }^{2}$ Unit of Pedagogy and Research in Biochemistry and Microbiology, Regional Unit of Higher Education (URES), \\ BP 150, Daloa, Cote D'Ivoire \\ Correspondence should be addressed to Beda M. Yapo, bedamarcel@yahoo.fr
}

Received 11 June 2011; Accepted 25 September 2011

Academic Editor: J. F. Vliegenthart

Copyright ( $) 2011$ Beda M. Yapo. This is an open access article distributed under the Creative Commons Attribution License, which permits unrestricted use, distribution, and reproduction in any medium, provided the original work is properly cited.

Rhamnogalacturonan II (RG-II) is a type of block copolymer of complex pectins that represents a quantitatively minor component of the primary cell walls of land (vascular) plants. The structural composition of RG-II is almost totally sequenced and appears to be remarkably conserved in all tracheophytes so far examined. The backbone of RG-II, released from complex (cell wall) pectins by endo-polygalacturonase (Endo-PG) treatment, has been found to contain up to $15(1 \rightarrow 4)$-linked- $\alpha$-D-GalpA units, some of which carry four well-defined side chains, often referred to as A-, B-, C-, and D-side chains. Nevertheless, the relative locations on the backbone of these four branches, especially the A chain, remain to be ascertained. A combination of different data suggests that neither the terminal nonreducing GalA nor the contiguous GalA unit is likely to be the branching point of the A chain, but probably the ninth GalA residue from the reducing end, assuming a minimum backbone length of $11(1 \rightarrow 4)$ linked- $\alpha$-D-GalpA. The latest reports on RG-II are here highlighted, with a provided update for the macrostructure and array of functionalities.

\section{Introduction}

The primary cell walls (PCWs) of plants encompass two independent and interacting polysaccharide networks, the first of which is a pectin network considered to be a matrix in which the second network (cellulose/hemicelluloses) is thought to be embedded $[1,2]$. Pectins are complex heteropolymers, composed mainly of $\alpha$-D-galactopyranosyluronic acid $(\alpha-\mathrm{D}-\mathrm{Gal} p \mathrm{~A})$ and some neutral glycosyl residues such as $\alpha$-L-rhamnopyranose ( $\alpha$-L-Rha $p), \alpha$-L-arabinofuranose $(\alpha$-L-Ara $f)$, and $\beta$-D-galactopyranose $(\beta$-D-Gal $p)$. The pectin network is generally believed to be formed with three block copolymers, namely, homogalacturonan (HG), rhamnogalacturonan-I (RG-I), and the "substituted galacturonan (SG)" rhamnogalacturonan-II (RG-II) [3, 4], though other pectic polysaccharide types, namely, xylogalacturonan $(\mathrm{XGA})$, apiogalacturonan $\left(\mathrm{A}_{\mathrm{p}} \mathrm{GA}\right)$, galacturonogalacturonan (GaGA), galactogalacturonan (GGA), and arabinogalacturonan $\left(\mathrm{A}_{\mathrm{r}} \mathrm{GA}\right)$, which are SGs, have also been purified from plant cell wall materials [5-8]. The pectic polysaccharide RG-II is a quantitatively minor component of the PCW, accounting hardly for $0.1 \%(\mathrm{w} / \mathrm{w})$ of the pectin-poor PCW of commelinoid-related monocots and for between 0.5 and $8.0 \%(\mathrm{w} / \mathrm{w})$ of the pectin-rich PCW of noncommelinoid-related monocots and dicots $[9,10]$. However, RGs-II are ubiquitous and remarkably conserved throughout vascular plants, allowing to believe that they hold specific function(s) in the cell wall. The demonstration that RG-II exists in primary walls predominantly as a dimer (dRG-II) that is covalently cross-linked by a borate diester is a major advance in our understanding of the structure and function of this pectic polysaccharide type [9]. The formation of dRG-II is required for the formation of the pectin network in muro that contributes to the mechanical strength and physical properties of the PCW and is essential to normal plant growth and development. The ability of dRG-II to be complexed with heavy metals such as lead and barium may also open a way for bioremediation and 
biodepollution of contaminated soils and waters. Some RGsII isolated from (pectins extracted from) cell wall materials (CWMs) of certain plants possessed potent immunological properties, while other RGs-II from other plants had shown no such activities [11], implying that further investigations are essential to assign a definite role to RGs-II for which some slight structural variations could explain the significant differences in terms of bioactivity [12]. Thus, a comprehensive knowledge of the structural composition and subunits arrangement of RG-II is required to better understand the potential functional versatility of RGs-II and to identify the possible pathway of biosynthesis of this polysaccharide type. Structural and macromolecular studies have shown that enzymatically (Endo-PG)-released RGsII are heteropolysaccharides of low molecular weight (5$10 \mathrm{kDa}$ ) having a linear backbone composed of 9-15 ( $1 \rightarrow$ 4)-linked- $\alpha$-D-GalpA units, partly branched with four welldefined oligosaccharide side chains, often referred to as A-, $\mathrm{B}-, \mathrm{C}-$, and $\mathrm{D}$-side chains. The relative positions and the exact branching points of these four branches, particularly the A chain and to a lesser extent the $\mathrm{C}$ chain on the backbone remain, however, to be pinpointed. While it has been proposed that the A chain is placed at the penultimate GalA of the backbone from the nonreducing end [12], more recent work from us [13] in combination with other previous studies $[14,15]$ allow to forward that neither the terminal nonreducing GalA nor the adjacent GalA residue is likely to be the branching site of the A chain, but most probably the ninth GalA residue from the reducing end, assuming a minimum backbone degree of polymerization of at least $11(1 \rightarrow 4)$-linked- $\alpha$-D-GalpA. This paper aims at highlighting the latest findings on RG-II and updating the structural features and array of (bio)functionalities of this highly complex block copolymer of pectins from the PCWs of land plants.

\section{Isolation and Purification}

The pectic polysaccharide RG-II was first isolated from the PCW of suspension-cultured sycamore cells by digestion with a highly purified Endo-PG and fractionations of the soluble products by ion-exchange chromatography (IEC) on a DEAE Sephadex A-25, followed by gel permeation (or size-exclusion) chromatography (GFC or SEC) equipped with agarose $5 \mathrm{~m}$ and then with Bio-Gel-P-10 filtration columns [16]. To date, RGs-II have almost always been isolated with similar (Endo-PG) methods, followed by SEC fractionations, often preceded by IEC purifications to mainly remove uncharged (neutral polysaccharide) and short oligogalacturonide materials. Sometimes, however, exo-polygalacturonases (Exo-PGs) have been combined to Endo-PGs $[17,18]$ with the aim of speeding up the hydrolytic process. Alternatively, less expensive crude liquefying enzyme preparations, possessing a wide range of pectinolytic and "hemicellulasic" activities, such as Driselases, Pectinases, and Rapidases, have been used for the solubilization of (relatively intact) RGs-II from plant tissues [19-23], owing to a high level of resistance to all known glycanase preparations except for the glycanases-rich cell-free extract of Penicillium daleae [15]. The resistance to most glycanases is thought to be conferred to by the four oligosaccharide branches attached to four GalA residues of the RG-II backbone due to steric hindrance, which explains why "intact" RGs-II are released from cell walls by Endo-PG treatment [24]. Presaponification $[25,26]$ of intact CWMs and non-alkaliextracted pectins, before treatment with Endo-PGs, may sometimes be necessary to effectively degrade HG and thus separate RG-II from RG-I. The fractionation, on appropriate high-resolution size-exclusion chromatographic (HRSEC) columns such as Superdex-75 HR 10/30 [19] Superose-12 HR 10/30 [27], Sephacryl S-100 HR 16/60 or Sephacryl S-200 HR 16/90 [10, 13], and their likes (e.g., Bio-Gel-P30) [28] of the (soluble) products of the enzymatic digests typically yields in molecular decreasing order, RG-I (Figure 2(I)), RG-II (Figure 2(II)), and oligogalacturonides (derived from Endo-PG-degraded unbranched HGs; Figure 2(III)). In case both dimer (dRG-II) and monomer (mRG-II) of rhamnogalacturonan II are present in the Endo-PG-generated products, the HRSEC chromatogram shows, in molecular weight decreasing order, RG-I, dRG-II (Figure 2( $\left(\mathrm{II}_{1}\right)$ ), mRGII (Figure $2\left(\mathrm{II}_{2}\right)$ ), and oligogalacturonide fractions.

\section{Structural Characteristics}

Among the so-called SGs, RG-II is undoubtedly the most complex and probably the most widespread structural components of the PCWs of land (vascular) plants. This polysaccharide type has indeed been characterized from the walls of some seedless vascular plants such as ferns (e.g., Ceratopteris thalictroides and Platycerium bifurcatum), horsetails (e.g., Equisetum hyemale), and lycopods (e.g., Lycopodium nummularifolium and Lycopodium scariosum), and from most (if not all) higher plant cell walls examined hitherto. Moreover, commercial enzymatic preparations from Aspergillus niger, marketed as Pectinol AC (Corning, Inc.), and fresh fruit and fermented beverages (red and white wines) have been found to contain RGs-II. Originally discovered in 1978 in polysaccharide fractions solubilized, from (intact) CWM of suspension-cultured Acer pseudoplatanus (sycamore) cells, with a highly purified endo-polygalacturonase (Endo-PG) preparation from Colletotrichum lindemuthianum [16], RGsII have since then been shown to possess a linear backbone of $(1 \rightarrow 4)$-linked $\alpha$-D-GalpA units carrying four well-defined oligosaccharide side chains (Figure 1). Thus, RGs-II are not structurally related to RGs-I, inasmuch as no Rhap units are present in the basal chain, but in three of the four authenticated side-chains (Figure 1, A-, B-, and Cside chains). The terminology "rhamnogalacturonan II" is therefore a somewhat misleading and was probably primarily given [16] for distinction sake from a previously purified (higher molecular weight) "rhamnogalacturonan" having both GalpA and Rhap units in the basal chain, from the same type of enzymatic digests [29]. To date, structural analyses have revealed that RGs-II are composed of at least 11 different glycosyl residues (Table 1), regardless of their anomeric $(\alpha, \beta)$, enantiomeric (D, L), ring (furanosyl, 


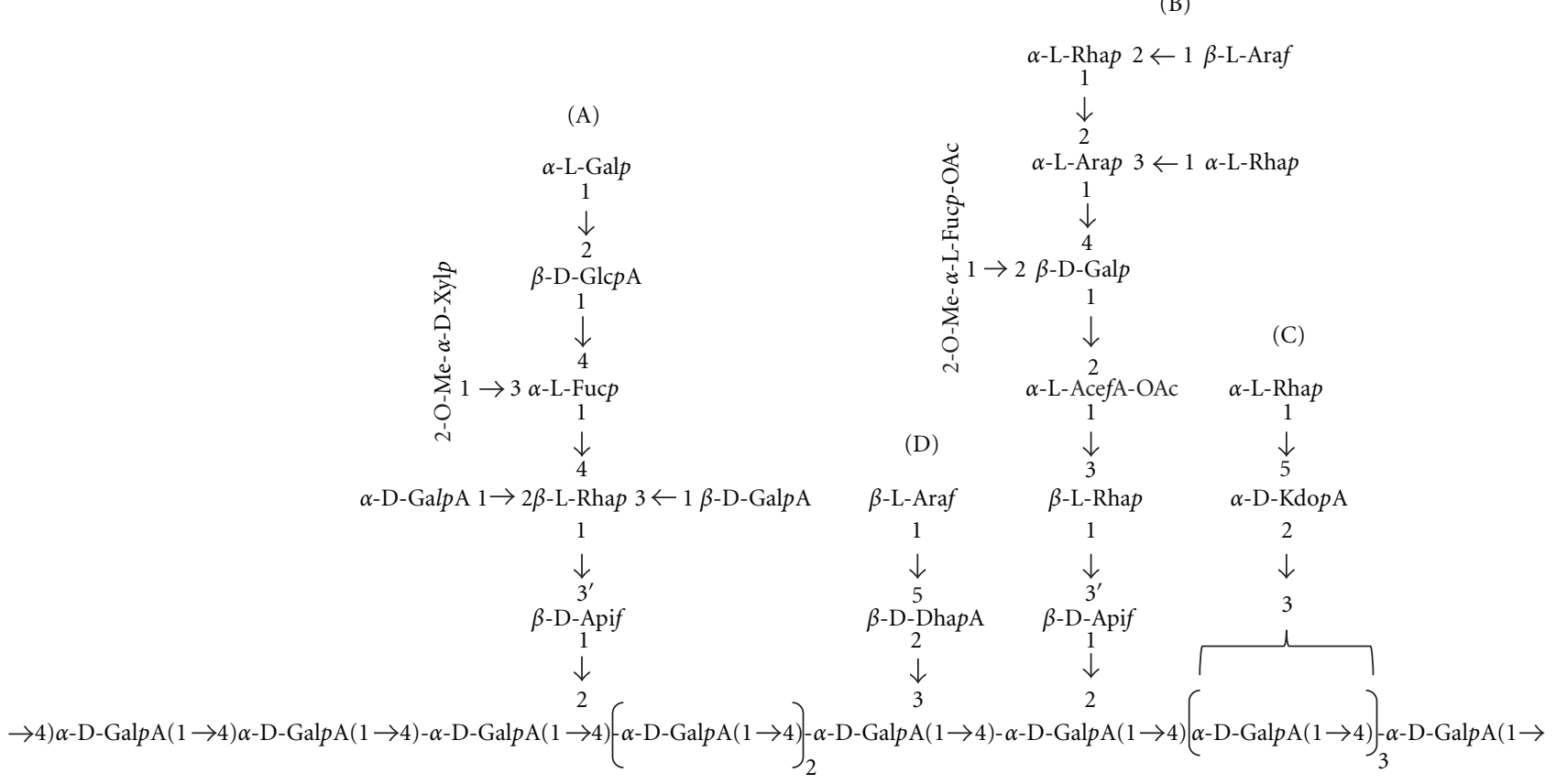

FIGURE 1: Schematic representation of rhamnogalacturonan II with a new proposal for the likely position of the A-side chain on the galacturonan backbone.

pyranosyl), and derivative ( $O$-methyl-ether and/or $O$-acetylester) forms. These are galacturonic acid (GalA), followed by rhamnose (Rha), arabinose (Ara), galactose (Gal), glucuronic acid (GlcA), apiose (Api; $3-C$-(hydroxymethyl)- $\beta$-Derythrose), 2-O-methyl-fucose (2-O-Me-Fuc), 2-O-methylxylose (2-O-Me-Xyl) [16], aceric acid (AceA; 3-C-carboxy-5deoxy-L-xylose) [30], 2-keto-3-deoxy-D-manno-octulosonic acid (KdoA) [31], and 3-deoxy-D-lyxo-heptulosaric acid (DhaA) [32]. It would therefore be cumbersome if the IUBIUPAC tentative rules (2-Carb-39.7) for carbohydrate nomenclature were adopted for naming this polysaccharide type [9]. Since the terms "rhamnogalacturonan II" and "RG-II" have become deeply entrenched in the vernacular and literature of plant cell wall research, it is reasonable to believe that only new workers in the field could probably find them "inappropriate" at first sight. The latter six sugars are seldom detected in plant materials. Moreover, no other known natural polysaccharides from plants are likely to contain these sugars, which are therefore often viewed as the RG-II characteristic, specific, or diagnostic glycosyl residues $[5,10,19]$. It should be underlined that the rare sugar L-Galp identified in RGs-II [18] from various sources is also a constitutional sugar of RGs-I from certain mucilages [33-35], and therefore it cannot be viewed as a specific glycosyl residue to RGs-II. Mono-Oor di-O-acetyl-esterification can occur at the $O-3$ position of AceA and at the $O-3 / O-4$ positions of $2-O-M e-F u c$. Furthermore, $\alpha$-L-Rhap units of RGs-II from some but not all pteridophytes and lycophytes have been found to be 3$O$-methyl-etherified [22]. Also, glucose (Glc) and mannose (Man) have been detected in some purified RGs-II [16, $17,36-38]$, but are usually considered to be impurities originating from neighbouring polysaccharides, especially noncellulosic cross-linking heteroglycans (formerly known as hemicelluloses). The glycosyl residues of RG-II are interconnected by more than 20 different glycosidic linkages, made up of at least 25 individual sugars. This results in formation of highly complex RG-II macromolecules with a linear $(1 \rightarrow 4)$-linked $\alpha$-D-galacturonan backbone, partially methyl-esterified at $C-6$ of GalpA residues and branched with four oligosaccharide chains of well-defined glycosyl residue and glycosyl linkage compositions (Figure 1). However, it is worth underlining that some structural features of RGsII need to be unequivocally ascertained. The first of them is a hypothetical fifth substitution that would occur, with a single nonreducing $\alpha$-L-Ara $f$ residue, at the $O-3$ position of either the seventh or eighth GalA residue of the backbone (from the reducing end), that is, the so-called E-side chain [12]. The second is the anomeric configurations of AceA and $\mathrm{D}$-Gal residues of the $\mathrm{B}$-chain, first reported to $\beta$ and $\alpha$ configurations, respectively, and later reassigned the opposite, that is, $\alpha$ and $\beta$ configurations. The third is the commonly identified disaccharide moiety $[\beta$-L-Araf $-(1 \rightarrow$ $2)-\alpha$-L-Rhap- $(1 \rightarrow]$ terminating the B-chain, which has more recently been schematically represented to be $[\beta$-L-Araf $-(1 \rightarrow$ 3)- $\alpha$-L-Rhap- $(1 \rightarrow]$ [9], though it might have been changed inadvertently. The fourth is the terminal nonreducing Galp residue of the A chain, which was primarily assigned to a D configuration and later reassigned an L configuration, thus showing the presence, in RGs-II, of a new rare sugar (the seventh), originally found in linseed mucilages [39]. Also, the anomeric configuration of the latter sugar is not known with certainty [22], though it is widely believed to be of an $\alpha$ configuration $[9,12,40]$. 


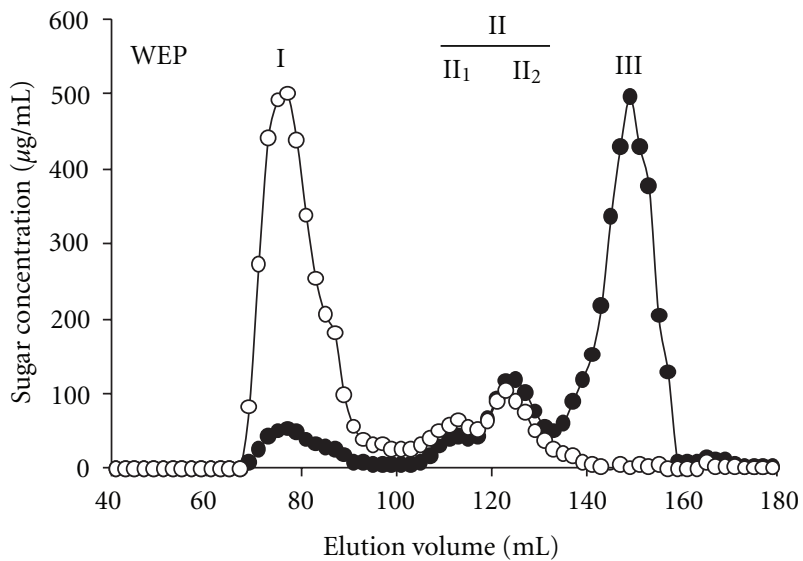

(a)

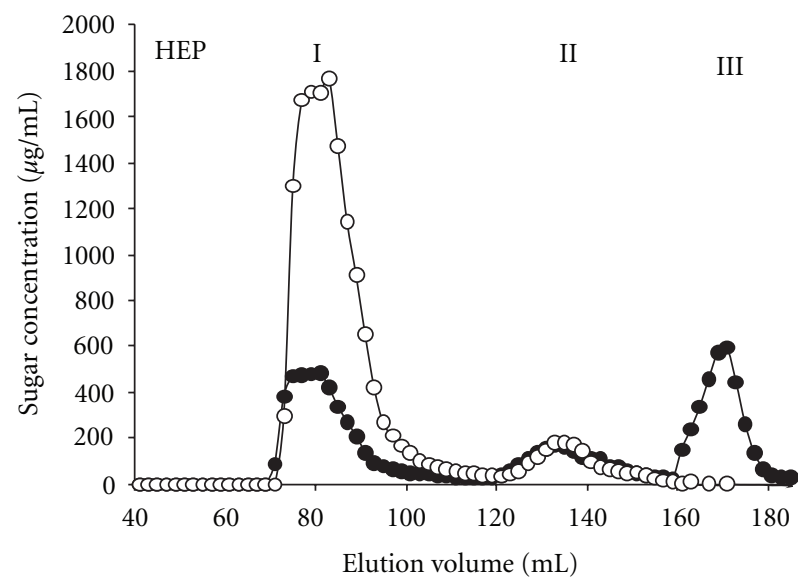

(c)

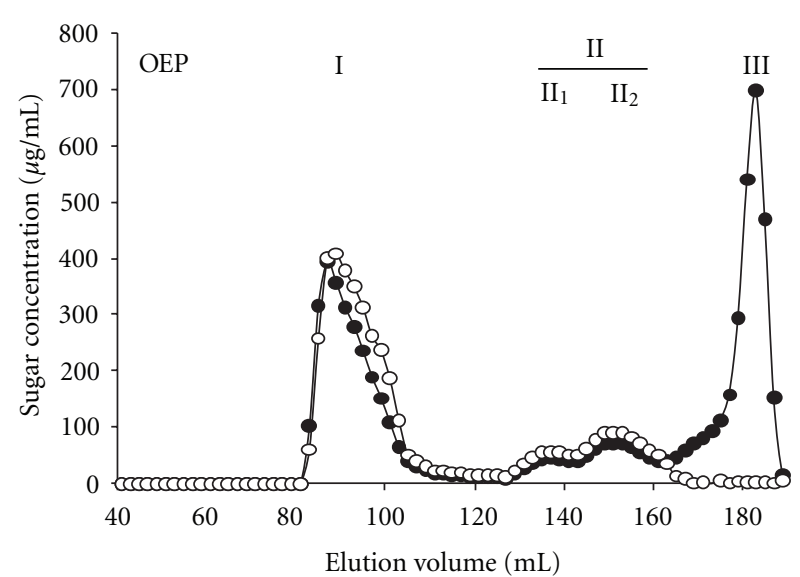

(b)

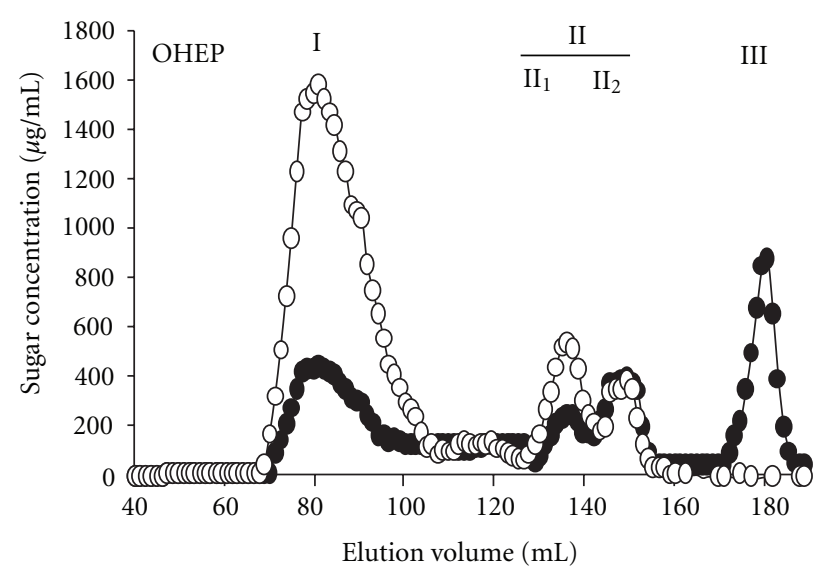

(d)

FIGURE 2: Size-exclusion chromatographic (SEC) fractionations of dialyzed Endo-PG-II-digested presaponified cold water-extracted pectins (WEPs), cold-potassium-oxalate extracted pectins (OEPs), hot dilute $(0.05 \mathrm{M})$ hydrochloric-acid-extracted pectins(HEPs), and cold dilute $(0.05 \mathrm{M})$ sodium-hydroxide-extracted pectins (OHEPs) from citrus peel CWM, showing in molecular weight decreasing order; rhamnogalacturonan I (fraction I), rhamnogalacturonan II dimer (fraction $\mathrm{II}_{1}$ ) and/or monomer (fraction $\mathrm{II}_{2}$ ), and oligogalacturonide (fraction III) populations. Neutral sugars (०); uronic acids $(\bullet)$.

\section{On the Relative Locations on the RG-II Backbone of the Four Branches}

The four oligosaccharide branches of RGs-II are often referred to as A-, B-, C-, and D-side chains to facilitate identification. However, the relative positions, on the backbone, of these side chains to one another is not known with certainty, though some studies have partly paved the way for possible elucidation. By converting the reducing end $\mathrm{D}$ GalA of an isolated RG-II monomer (mRG-II), from red wine, to L-galactonic acid (by treatment with $\mathrm{NaBH}_{4}$ ) and fragmenting the resulting $\mathrm{NaBH}_{4}$-reduced RG-II monomer (mRG-II-ol) with a cell-free extract from $P$. daleae, a group of workers [15] found that the backbone of the starting RGII was likely to be substituted, at the $O-2$ and $O-3$ positions of the fifth and sixth GalA residues from the reducing end, by the AceA-(and 2-O-Me-Fuc-) containing nonasaccharide (B-side chain) and the DhaA-containing disaccharide (Dside chain), respectively. The exact branching point of the KdoA-containing disaccharide (C-chain) has not been pinpointed on the RG-II backbone, but could be located on the second, the third, or the fourth GalA residue from the reducing end, considering the authors conclusions that the $B, C$, and D chains should be confined to the five $(1 \rightarrow$ 4)-linked $\alpha$-D-GalpA units closer to the reducing end of the RG-II macromolecule. In contrast, this study did not give any information about the likely branching site of the 2-O-Me-Xyl-containing octasaccharide (A chain) on the backbone, because the main fragment generated by the RGII-fragmenting glycanases (produced by $P$. daleae) was not found enriched with it. Conformational preferences have been proposed for the four oligosaccharide side chains and 
TABLe 1: Glycosyl residue composition (mol\%) and molecular weight $\left(M_{w}\right)$ of rhamnogalacturonan II monomers (mRGs-II) and dimers (dRGs-II) from various plant cell wall pectins.

\begin{tabular}{|c|c|c|c|c|c|c|c|c|c|}
\hline Sugars (mol\%) & $\begin{array}{l}\text { Sycamore }^{\mathrm{a}} \\
\text { mRG-II }\end{array}$ & $\begin{array}{c}\text { Arabidopsisthaliana }^{\mathrm{b}} \\
\text { mRG-II }\end{array}$ & $\begin{array}{c}\text { Sugar Beet } \\
\text { dRG-II }\end{array}$ & $\begin{array}{c}\text { Red Beet }^{\mathrm{d}} \\
\text { mRG-II }\end{array}$ & $\begin{array}{c}\text { Red Wine }^{\mathrm{e}} \\
\text { mRG-II }\end{array}$ & $\begin{array}{l}\text { Apple }^{\mathrm{f}} \\
\text { mRG-II }\end{array}$ & $\begin{array}{l}\text { Carrot }^{\mathrm{f}} \\
\text { mRG-II }\end{array}$ & $\begin{array}{l}\text { Tomato }^{\mathrm{f}} \\
\text { mRG-II }\end{array}$ & $\begin{array}{l}\text { Citrus }^{\mathrm{g}} \\
\text { mRG-II }\end{array}$ \\
\hline GalA & 31.2 & 44 & 37.7 & 37.4 & 37.0 & 33 & 28.3 & 35.5 & 43.3 \\
\hline Rha & 12.4 & 10 & 11.3 & 14.2 & 16.0 & 17.4 & 14.3 & 11.6 & 16.9 \\
\hline Fuc & $2.8-4.0$ & 3 & 1.6 & 2.2 & 3.0 & 5.5 & 4.7 & 4 & 4.2 \\
\hline Ara & 10.0 & 17 & 10.9 & 12.8 & 11.0 & 16.8 & 14 & 12.4 & 12.1 \\
\hline Xyl & 2.0 & 3 & nd & nd & nd & nd & nd & nd & 2.6 \\
\hline Glc & 2.0 & 2 & nd & nd & nd & nd & nd & nd & 1.3 \\
\hline Gal & 9.0 & 9 & 12.4 & 11.8 & 6.0 & 6.4 & 7.8 & 8.1 & 10.5 \\
\hline GlcA & 3.2 & 2 & 7 & 5.5 & 5.0 & 2.8 & 2.7 & 4.4 & 1.5 \\
\hline 2-O-Me-Fuc & 3.5 & 1 & 3.3 & 3.9 & 4.0 & 4.8 & 5 & 4.4 & 0.7 \\
\hline 2-O-Me-Xyl & 4.8 & 2 & 4.9 & 3.4 & 3.0 & 2.9 & 4 & 3.3 & 2.4 \\
\hline Api & $6.0-12.2$ & 3 & 4.5 & 8.5 & 6.0 & 5.4 & 9.1 & 7 & 1.6 \\
\hline AceA & 3.5 & 1 & nd & nd & 2.0 & 1.5 & 3.5 & 2.3 & 0.6 \\
\hline KdoA & 3.5 & 3 & 5.3 & ND & 4.0 & 1.1 & 2.3 & 4 & 0.4 \\
\hline DhaA & 3.5 & ND & 5.3 & ND & 3.0 & 2.5 & 4.6 & 3 & ND \\
\hline Total sugar & $99.0-100.4$ & 100 & 104.2 & 99.7 & 100 & 100.1 & 100.3 & 100 & 98.1 \\
\hline$M_{w}(\mathrm{kDa})$ & $4.5-5.5$ & ND & $9.50-10.5$ & 4.3 & $4.5-4.7$ & 4.8 & 4.8 & 4.8 & $\mathrm{ND}$ \\
\hline
\end{tabular}

${ }^{\mathrm{a}}[36,43,70] ;{ }^{\mathrm{b}}[36] ;{ }^{\mathrm{c}}[43] ;{ }^{\mathrm{d}}[38] ;{ }^{\mathrm{e}}[44] ;{ }^{\mathrm{f}}[19] ;{ }^{\mathrm{g}}[10,13]$.

ND: not determined.

nd: not detected.

partially validated by sequential nuclear overhauser effects (NOEs) in NMR investigation of saponified mRG-II and mRG-II-ol, thus allowing the penultimate GalA residue from the nonreducing end of the RG-II macromolecule to be designated as the branching site of the A-side chain [12]. Nevertheless, the fact that the terminal nonreducing end of partial-acid-hydrolysis- (PAH-) generated sycamore RG-II backbone fragment, with a $\mathrm{DP} \sim 12$, appeared to be heavily susceptible to Exo-PG preparations [14] is not likely to support the indicated branching point of the Aside chain on the RG-II backbone. On the other hand, Endo-PG-isolated RG-II from mild acid-extracted (citrus) pectins had an intact backbone DP [13], and the cell-free extract of $P$. daleae fragmented mRG-II-ol from the terminal nonreducing end of the backbone [15]. All these data, taken together, suggest that neither the terminal nonreducing GalA nor the adjacent (i.e., the penultimate) GalA residue of the RG-II backbone is likely to be the branching point of the A chain, but either the sixth GalA residue, assuming that one of the backbone GalA residues can bear two oligosaccharide side chains owing to the identification of $(1 \rightarrow 2,3,4)$-linked $\alpha$-D-GalpA residues in PAH products of RGs-II $[19,41]$ or most probably the ninth residue, as represented in Figure 1, from the reducing end, assuming a minimum backbone DP of $11(1 \rightarrow 4)$-linked $\alpha$-D-GalpA residues. This could explain the reason why it has apparently been separated from the other three (B-, C-, and D-) side chains of the RG-II macromolecule by the action of the RG-II-fragmenting glycanases of the cell-free extract of $P$. daleae.

\section{On the In Muro Existence and Interconversion of RG-II Dimers and Monomers}

Since the early reports on borate-cross-linked RG-II dimers (dRG-II or B-dRG-II) in the PCWs of Raphanus sativus (radish) roots, Beta vulgaris (sugar beet) pulp, suspensioncultured A. pseudoplatanus (sycamore) cells, etiolated pea stems, and red wine [41-44], a widely held view is that this polysaccharide type exists predominantly in the form of dRG-II in muro [9, 12, 40,45], which is supported by later work [10, 46, 47]. In vitro, dRG-II formation is a selfassembly process which is the result of the cross-linking of two mRG-II chains via the two Apif-containing A-side chains on both RG-II macromolecule strands, with theoretically two possible diastereoisomers $[48,49]$. However, it remains to be known whether dRG-II formation, in muro, is also a self-assembly process or involves at least partly some (bio-)chemically catalyzed reactions. The formation of dRGII would also be fostered by the flexible enough character of the Apif residue-containing linkages of each A-side chain on either side. It has been suggested, by computational, AFM, and conformational studies that the overall shape of mRGII resembles a quite flat disc-like structure with a thickness of approximately $1.7 \mathrm{~nm}$, whereas that of dRG-II may look like a compact flat disk [12], resulting from a parallel-wise stack-up on each other of two flattened (mRG-II) disks. In vitro studies have shown that different factors such as $\mathrm{pH}$, temperature, cation-chelating agents, and cation type can influence the interconversion of dRG-II and mRG-II. In 
aqueous media with $\mathrm{pH}<2.0$, the borate diester linkages of dRGs-II are totally hydrolyzed, at ambient temperature, resulting in formation of mRGs-II, whereas between $\mathrm{pH}$ 2.0 and 4.0, only a partial hydrolysis of the borate diester linkages occurs, and hence both dRG-II and mRG-II could coexist in comparable proportions. At $\mathrm{pH}>4.0$, the borate diester linkages are amply stable, and therefore dRG-II is predominant over mRG-II. At $\mathrm{pH}$ values between 2.4 and 6.2 , treatment of a pair of mRG-II chains with an equimolar amount of boric acid, in the presence of various multivalent cations $\left(\mathrm{Ba}^{2+}, \mathrm{Sr}^{2+}, \mathrm{Pb}^{2+}, \mathrm{La}^{3+}, \mathrm{Ce}^{3+}, \mathrm{Pr}^{3+}, \mathrm{Nd}^{3+}\right.$, and $\left.\mathrm{Eu}^{3+}\right)$ has been observed to rapidly promote formation of dRG-II $[9,12,44]$. As for the divalent cation $\mathrm{Ca}^{2+}$, it could favour formation and/or stabilization of dRGs-II in muro [50]. The ratio of $\mathrm{mRG}$-II to dRGII may be determined by the boron status of the cell wall [41]. In contrast, the addition of strong $\mathrm{Ca}^{2+}$-sequestering agents, namely, EDTA and CDTA to dRG-II preparations resulted in partial or complete decomposition of dRGs-II into mRGs-II, respectively [50, 51]. In consistent with these reports, it has more recently been observed that both dRG-II and mRG-II populations are present in Endo-PG-digested water-extracted pectins (WEPs) and oxalate extracted pectins (OEPs)- at $\mathrm{pH} 4.5$ and $25^{\circ} \mathrm{C}$, whereas only $\mathrm{mRG}$-II populations are present in hot dilute $(0.05 \mathrm{M})$ hydrochloric-acid-extracted pectin (HEP) from CWMs of different monocot species (Ananas comosus (pineapple), Musa acuminata (banana), and Allium porrum (leek)) and dicots (Cucumis sativus (cucumber), Foeniculum vulgare (fennel), B. vulgaris, and Citrus) (see, e.g., Figure 2). Furthermore, the Apif content of the purified mRG-II from HEP from citrus peel [13] was significantly lower than the Apif content of otherwise isolated RGs-II (from pectins) from CWMs of other plant sources (Table 1). These data support involvement of Apif in formation of the tetrahedral $1: 2$ borate diol diester cross-links in such a way that its degradation to some extent, probably simultaneously with borate diester linkages, by acid agents, leads to a complete decay of dRG-II into mRGs-II. A comparison of the latter data [13] with the data whereby dRG-II (from CWM of sugar beet) has been totally hydrolyzed with $0.5 \mathrm{M}$ $\mathrm{HCl}$ (i.e., a tenfold higher acid concentration) at $25^{\circ} \mathrm{C}$ for $30 \mathrm{~min}$ [43], suggests the existence of interactive effects between (hydrochloric) acid concentration and temperature. Rather surprising, however, has been the observation [10] that both dRG-II and mRG-II populations (Figure 2) are present in Endo-PG-generated products from cold dilute $(0.05 \mathrm{M}) \mathrm{NaOH}$-solubilized pectins (OHEPs) from the acid pre-treated citrus peel cell wall residue, thereby suggesting that acid-induced dRG-II monomerization is slower in wall-bound dRG-II than in solubilized dRG-II. This is in agreement with the observed considerable differences in the concentration and stability of the borate ester bonds between denaturated cell walls and solubilized dRG-II [51]. On the other hand, spontaneous in vitro decay of dRG-II into mRGsII has been observed in $\mathrm{Ca}^{2+}$-free medium [50], suggesting the existence of more than one way of conversion of dRGs-II into mRGs-II or vice versa. Both mRG-II and dRG-II have the same (or very similar) glycosyl residue compositions, but are distinguished from each other by the presence in the latter of borate ester cross-links via $\left(1 \rightarrow 2,3,3^{\prime}\right)$-linked Apif residues (of the A chain), and hence by the boron content, and the molecular weight $\left(M_{w}\right)$ values, which are $\sim 5.0$ and $\sim 10.0 \mathrm{kDa}$, respectively.

\section{The RG-II Proportion in PCWs and Complex Pectins}

There is a considerable body of evidence showing that the pectic polysaccharide RG-II is present, albeit in different amounts, in the walls of all gymnosperms and angiosperms [9] and probably in the walls of all pteridophytes and lycophytes. The RG-II content of the primary cell wall may be correlated to a plant's boron requirement. RGsII can account for between $0.5 \%$ and $8 \%(\mathrm{w} / \mathrm{w})$ of the pectin-rich PCW of dicots, noncommelinoid-related and nongraminaceous monocots, and gymnosperms, but for less than $0.1 \%(\mathrm{w} / \mathrm{w})$ of the pectin-poor PCW of the commelinoid-related monocots and poaceae $[9,10,17]$, and hence are quantitatively minor cell wall polysaccharides (CWPs). Although thought to account for $10-11 \%$ (w/w) of (cell wall) pectins [52], the RG-II content of pectins from CWMs of different monocotyledonous and dicotyledonous species has been found to be less than $5 \%$ (w/w) [10]. Furthermore, RG-II fraction represents $c a . \sim 1.5 \%(\mathrm{w} / \mathrm{w})$ of Pectinol AC [30], and white and red wines contain $\sim 20$ and $\sim 150 \mathrm{mg}$ of RG-II/L, respectively. Moreover, RG-II accounts for $20 \%(\mathrm{w} / \mathrm{w})$ of alcohol-precipitable polysaccharides from red wine, thereby occurring as dominant polysaccharide components of wines and other beverages obtained by fermentation of juice from fruits and vegetables $[9,19,41]$.

\section{Degree of Polymerization}

The $M_{w}$ of RGs-II has been determined by various analytical methods, such as reducing end group, high pressure size exclusion chromatography combined to on-line differential refractive index detector and to low-, right- or multiangle laser light scattering detector (HPSEC-RI/LALLS/RALLS/ MALLS), size exclusion chromatography combined with inductively coupled mass spectrometry (SEC/ICP-MS), and matrix-assisted laser desorption ionisation time of flight with mass spectrometry (MALDI-TOF/MS). The $M_{w}$ s of mRGII and dRG-II are typically found to be $\sim 5.0$ and $10.0 \mathrm{kDa}$, respectively, irrespective of the polysaccharide origin, though values of $\sim 4.0 \mathrm{kDa}$ [38] (Table 1) and up to $25.0 \mathrm{kDa}$ [51] have also been reported, probably due to partial degradation of RG-II in the former case and the presence of HG runs at the ends of RG-II in the latter. Assuming that the four oligosaccharide side chains (see Figure 1) of RGs-II are structurally conserved throughout the PCWs of plants, the DP of the backbone of RGs-II can be theoretically estimated from the knowledge of the glycosyl residue composition (in molar) and $M_{w}$. The calculated DP values, on the basis of this assumption, from the data presented in Table 1, range from $\sim 6$ to $11(1 \rightarrow 4)$-linked $\alpha$-D-GalpA units. Most often, however, the RG-II backbone is isolated by submitting purified (whole) RGs-II to PAH (e.g., $0.1 \mathrm{M} \mathrm{TFA}, 80^{\circ} \mathrm{C}$, $16 \mathrm{~h}$ [14], 
and $0.1 \mathrm{M}$ TFA, $40^{\circ} \mathrm{C}, 16 \mathrm{~h}+0.1 \mathrm{M}$ TFA, $100^{\circ} \mathrm{C}, 1 \mathrm{~h} \mathrm{[21]),}$ because this polysaccharide type has proven to be resistant to all enzymes (glycanases) known to specifically degrade (natural) polysaccharides, and fractionating the resulting hydrolysates by IEC/SEC. PAH usually affords the isolation of the RG-II backbone as well as the side chains and can be made selective to (some of) them by modifying the hydrolytic conditions, particularly temperature and time. Once purified, the RG-II backbone fragments are usually analyzed by high pressure anion exchange chromatography with a pulsed amperometric detector (HPAEC-PAD) and DPs are estimated by cochromatographying (comparison of elution times) with enzymatically produced oligogalacturonide standards from commercial polygalacturonic acids (PGAs). The main disadvantage of PAH is the fact that it generates several RG-II backbone fragments with DPs ranging from 2 up to $15(1 \rightarrow 4)$-linked $\alpha$-D-GalpA units rather than an "intact" backbone chain, which renders rather demanding the estimation of the actual backbone length. Remarkable is, however, the observation that PAH-generated RG-II backbone fragments (but not intact starting RGs-II) are completely hydrolyzed by homogenous Endo-PG preparations $[14,41]$, which further substantiates that the RG-II backbone does consist of unbranched $(1 \rightarrow 4)$-linked $\alpha$-DGalpA units, and that the RG-II side chains are accountable for resistance to almost all known glycanases including the former. However, it is not known with certainty if all the four side chain residues are pruned off the RG-II backbone by PAH to furnish (completely unbranched) galacturonan fragments. Nevertheless, it can be thought so, owing to the unusually high acid lability of the glycosyl residues (2Apif, $1 \mathrm{Dha} p \mathrm{~A}, 1 \mathrm{Kdo} p \mathrm{~A})$ via which the four branches appeared to be connected to the backbone. This would also explain why Apif is often determined in nonstoichiometric quantities and that DhapA and KdopA are rarely detected in RGs-II from mild acid-extracted pectins and acid-pretreated CWMs $[10,13]$. Moreover, the cochromatographying of these PAHgenerated backbone fragments with different oligoGalA standards provides further evidence for the apparently linear and "bare" character of the so-produced backbone fragments. By the different analytical methods aforementioned, a DP7-9 has been reported, for example, for sugar beet RG-II [21], DP7-11 for sycamore RG-II [14] and DP8-15 for red wine RG-II [41]. Nonetheless, the linear backbone of RGs-II is commonly assumed to be made up of at least $9(1 \rightarrow 4)$-linked $\alpha$-D-GalpA units, on the basis of the report that this being the most abundant in sycamore cell wall RG-II [14].

\section{On the Structural Conservation of RG-II throughout All Land (Vascular) Plants}

A widely held view is that RGs-II are highly conserved throughout the plant kingdom $[9,24,53-55]$ to such an extent that the singular term "rhamnogalacturonan II (RGII)" rather than the plural term "rhamnogalacturonans II (RGs-II)" is almost always employed, implying a unique (invariable) macromolecule. This can be owed to the report of similar $M_{w}$ values (Table 1) and the same four oligosaccharide side chains whatever the RG-II origin (plant cell walls, Pectinol AC, fermented fruit and vegetable juices, and processed wines). The primary cell wall requirement for boron may also be one of the main selection pressures that have maintained the structure of RG-II "unchanged" in the plant kingdom during evolution [56]. Nevertheless, some structurally small intra- and intervariations, which may be functionally important, have been noted in RGs-II from diverse sources. Typical intravariations are the finding of varying backbone DPs (8-15) and methyl-esterification degrees (DM) for four RG-II fractions purified from red wine, which has facilitated their separation by HPAEC owing to differences in (negative) charge density [41]. An example of intervariations is the structural difference observed between Cryptomeria japonica (sugi) and A. pseudoplatanus (sycamore) cell walls RGs-II [28]. Also, the B-side chain can contain from seven to nine monosaccharides depending on whether the terminal nonreducing $\beta$-L-Araf and/or $\alpha$-LRhap residues are present or not [57]. Furthermore, the latter two sugars and the terminal nonreducing $\mathrm{L}-\mathrm{Gal} p$ residue of the A-side chain have been found in nonstoichiometrical amounts in sycamore and red wine RGs-II $[14,19]$. On the other hand, the RG-II synthesized by the Arabidopsis mur1 mutant was found to contain L-Galp in lieu of L-Fucp in the wild-type, and RG-II from the walls of nolac-H18 tobacco callus mutant lacked the $\alpha$-L-Gal $p-(1 \rightarrow 2)-\beta$-D-GlcpA- $(1 \rightarrow$ portion of the A-side chain [9]. Nevertheless, it remains to be clarified if the nolac-H18 tobacco mutant really affects the RG-II structure, inasmuch as the enzyme encoded by nolacH18 mutant is more likely involved in xylan biosynthesis during secondary cell wall (SCW) formation. Such variations, albeit slight, could result in significant differences in the functional properties of RGs-II [12]. On the other hand, the differences in the RG-II backbone DP, DM and de-methylesterification pattern (DMEP) may imply the existence of different RG-II populations holding miscellaneous functions within plant cell walls, though such differences may possibly originate from the action of different polygalacturonases (PGs) and pectin-methylesterases (PMEs) present in the fermentation medium during wine processing.

\section{Functional Properties}

9.1. In Muro Functionalities. Immunocytochemical studies have shown that RGs-II are enriched near the plasma membrane and in all the compartments of the PCW, but are almost absent from the middle lamellae $[58,59]$. Although being a structurally highly complex and a quantitatively minor component of PCWs of plants, the ubiquitous character of RGs-II, the conserved glycosyl sequence of RGs-II in taxonomically diverse plants, and the appearance of RGs-II early in the evolution of land (vascular) plants strongly suggest that this pectic polysaccharide type should play a fundamental role in the wall function and in the life of plants. This may be the main reason why very few mutants with altered RG-II have been identified, although many genes must be involved in RG-II biosynthesis [60]. The 
demonstration that RG-II exists in PCWs predominantly as a dimer that is covalently cross-linked by a borate diester is a major advance in our understanding of the structure and function of this pectic polysaccharide in the PCW pectic network [9]. RG-II dimerization is, indeed, believed to be a sine qua noncondition for formation of a three-dimensional pectin network in muro, which contributes to the mechanical properties of the PCW and reinforces the wall. Additionally, analyses of mutations that alter the structure of RG-II indicate that borate-diester cross-links between Apif residues in RGs-II are also important for strengthening the wall, and promoting intercellular adherence, and normal cell growth and development in tracheophytes. Like HG, RGs-II may be attached, as side chain, to a scaffold RG-I structure to form the pectin matrix, controlling the wall integrity $[61,62]$. On the other hand, RG-II is believed to be covalently linked, via the $O-1$ and/or $O-4$ positions of the terminal reducing and nonreducing GalA residues of its backbone, to linear HG $[24,63]$, because both have a backbone consisting of GalA units only and are chromatographically separable only after treatment of intact CWMs and (extracted) complex pectins with Endo-PG-rich enzymatic preparations [9, 10, 27]. Additionally, advanced proofs to explain possible covalent linkage between HG and RG-II are the isolation, from red wine, of RGs-II of varying backbone length as aforementioned; the difference that $>95 \%$ of wall-bound $\mathrm{dRG}-\mathrm{II}$ are converted into mRG-II by treatment with $50 \mathrm{mM}$ CDTA, $\mathrm{pH} 6.5$, compared to only 30 to $40 \%$ from presolubilized dRG-II [51]; the fact that aqueous potassium phosphatesolubilized high molecular weight (HMW) RG-II materials from Chenopodium album $(>25 \mathrm{kD})$ and $A$. thaliana $\left(M_{w}>\right.$ $100 \mathrm{kD}$ ) are decreased to low molecular weight (LMW) RG-II materials $(\sim 5-10 \mathrm{kD})$ by treating them with EndoPG/Exo-PG [18]. That the RG-II core is linearly connected to unbranched HG moiety of the main chain of complex pectins [3], to the backbone of RG-I [61] and/or to HG chains which are side chains of the RG-I core [63], is not yet irrefutably evidenced. RGs-II are also required for normal growth and development of plants in that changes in the wall properties and pore size that result from decreased borate cross-linking of pectin RG-II chains may lead to many of the symptoms associated with boron deficiency in plants $[9,51]$. Boron is an essential micronutrient for (the cells of growing) plants and is thought to be mainly provided by dRG-II. Dwarfism of $A$. thaliana mur1 mutant, deficient in L-fucose, would partly be the consequence of substantial alterations affecting dRG-II. More recently also, pollen tube growth and elongation in $A$. thaliana seemed to be conditioned by the synthesis of the RG-II diagnostic glycosyl residue KdoA [64]. The observation that any alteration in the structure and/or binding ability of RG-II leads to severe growth defects related to mechanical instabilities is obviously in line with the essential architectural role that RG-II may play in the cell wall [12]. In muro, dRGs-II are able to bind heavy metals, the physiological significance of which is not known with certainty, though it may allow plants to grow in the soils which contain elevated amounts of toxic cations [65], thereby being potential bioremediation agents for reducing heavy metal toxicity level in polluted soils.
9.2. Out of Muro Functionalities. The functional properties of RGs-II are still to be clearly described out of muro, and therefore purified RGs-II are somewhat in quest of function. Nevertheless, they may be effective "scavengers" of heavy metal cations. Many (processed) wines contain trace amounts of heavy metals such as lead $\left(\mathrm{Pb}^{2+}\right)$, barium $\left(\mathrm{Ba}^{2+}\right)$, and strontium $\left(\mathrm{Sr}^{2+}\right)$, most of which are complexed with dRGs-II [65] and remain so in the intestine of rats and unabsorbed into the blood stream, thereby decreasing intestinal absorption and tissue accumulation of lead [66]. However, chronic oral administration of dRG-II failed to accelerate body detoxification after chronic lead exposure in rats, suggesting that RG-II may have little therapeutic value for lead detoxification $[9,67]$. The ability of dRG-II to be complexed with heavy metals may also open a way for biodepollution of contaminated waters. Furthermore, RG-II-containing pectin-like structure (bupleuran) from Bupleurum falcatum has shown effective antiulcer activities [68], which might be at least partly due to the presence of RG-II. Also, RG-II from the leaves of Panax ginseng C.A. Meyer as well as RG-II-like polysaccharide from the rhizomes of Atractylodes lancea DC has exerted potent intestinal immune system modulating activity, but an isolated RGII from bupleuran, which is a pharmacologically active pectin, has exhibited no such activities [12, 69], implying that further investigations are essential to assign a definite role to RGs-II for which some slight structural variations could explain the observed significant differences in terms of bioactivity [12]. Nevertheless, the demonstration that some fresh and fermented beverages, more particularly red and white wines, contain relatively high amounts $(20-150 \mathrm{mg} / \mathrm{L})$ of RGs-II, that RGs-II bind heavy-metals, and that some RGs-II possess potent immunomodulating properties are so many elements that account for increasing interest and research, aiming at determining with much precision the fine structure of RGs-II and related functions in muro as well as after purification, notably in human nutrition and health.

\section{Concluding Remarks and Perspective}

Rhamnogalacturonans II are probably not only the most complex but also the most conserved cell wall polysaccharides, in terms of glycosyl residue composition and structural organization. Although the different structural subunits of rhamnogalacturonans II are now almost fully identified, the relative positions and branching points of the four authenticated oligosaccharide branches, more particularly the A- and C-side chains, and their spatial orientations, on the main chain, remain a big challenge for scientists to cope with. This structural puzzle may be related to the rather poor knowledge about RG-II biosynthesis and in and out of muro functional properties. The quasiabsence of rhamnogalacturonans II from the middle lamellae and their principal location to the primary cell wall suggests that this pectic polysaccharide type mainly holds structural functions, probably in conjunction with other (pectic) polysaccharides, notably homogalacturonan and rhamnogalacturonan I. They could therefore play fundamental role 
in the cell wall assembly and function. Thus, in-depth structure-function relationship may be ascertained by carrying out comparative studies of the mechanical and physical properties of (modelled) rhamnogalacturonan II-free cell walls to rhamnogalacturonan-II-rich cell walls and/or to cell walls containing altered rhamnogalacturonan II. Also, variation in the ratio of rhamnogalacturonan II dimer to monomer of (modeled) cell wall may provide interesting information as to the principal activity of this polysaccharide type in muro. We may therefore have a short or long way to go to completely unravel the structural and molecular features and the miscellaneous associated (bio)functions of rhamnogalacturonan II, one of the most complex and intriguing biopolymers from plant origin.

\section{Acknowledgments}

The author wants to thank Yeshua Ewrade for his assistance and help with this paper. Part of the work reported here is from the author's final term Ph.D. thesis studies carried out at the French Research Institute INRA of Nantes (France) under the cosupervision of Dr. Jean-François Thibault and Dr. Marie-Christine Ralet whose contributions are also acknowledged.

\section{References}

[1] N. C. Carpita and D. M. Gibeaut, "Structural models of primary cell walls in flowering plants: consistency of molecular structure with the physical properties of the walls during growth," Plant Journal, vol. 3, no. 1, pp. 1-30, 1993.

[2] N. Carpita and M. McCann, "The cell wall," in Biochemistry and Molecular Biology of Plants, B. Buchanan, W. Gruissem, and R. Jones, Eds., pp. 52-108, American Society of Plant Physiologists, Maryland, Md, USA, 2000.

[3] M. A. O’Neill, P. Albersheim, and A. Darvill, "The pectic polysaccharides of primary cell walls," in Methods in Plant Biochemistry, D. M. Dey, Ed., pp. 415-441, Academic Press, London, UK, 1990.

[4] M. A. O’Neill and W. S. York, “The composition and structure of plant primary cell walls," in The plant cell wall, J. K. C. Rose, Ed., pp. 1-54, Blackwell/CRC, Boca Raton, FLa, USA, 2003.

[5] H. A. Schols and A. G. J. Voragen, "Complex pectins: structure elucidation using enzymes," in Pectins and Pectinases, J. Visser and A. G. J. Voragen, Eds., pp. 3-19, Elsevier Science, Amsterdam, The Netherlands, 1996.

[6] R. G. Ovodova, S. V. Popov, O. A. Bushneva et al., "Branching of the galacturonan backbone of comaruman, a pectin from the marsh cinquefoil Comarum palustre L," Biochemistry (Moscow), vol. 71, no. 5, pp. 538-542, 2006.

[7] B. M. Yapo, "Pineapple and banana pectins comprise fewer homogalacturonan building blocks with a smaller degree of polymerization as compared with yellow passion fruit and lemon pectins: implication for gelling properties," Biomacromolecules, vol. 10, no. 4, pp. 717-721, 2009.

[8] B. M. Yapo, "On the rich pectin repertoire and functional versatility: an emphasis on the overlooked block co-polymers," Research \& Reviews in Polymer, vol. 1, no. 2, pp. 151-163, 2011.

[9] M. A. O'Neill, T. Ishii, P. Albersheim, and A. G. Darvill, "Rhamnogalacturonan II: structure and function of a borate cross-linked cell wall pectic polysaccharide," Annual Review of Plant Biology, vol. 55, pp. 109-139, 2004.

[10] B. M. Yapo, Study of the structural variability of pectins, Ph.D. thesis, Université de Nantes, Nantes, France, 2007.

[11] K. W. Yu, H. Kiyohara, T. Matsumoto, H. C. Yang, and H. Yamada, "Characterization of pectic polysaccharides having intestinal immune system modulating activity from rhizomes of Atractylodes lancea DC," Carbohydrate Polymers, vol. 46, no. 2, pp. 125-134, 2001.

[12] S. Pérez, M. A. Rodríguez-Carvajal, and T. Doco, "A complex plant cell wall polysaccharide: rhamnogalacturonan II. A structure in quest of a function," Biochimie, vol. 85, no. 1-2, pp. 109-121, 2003.

[13] B. M. Yapo, P. Lerouge, J. F. Thibault, and M. C. Ralet, "Pectins from citrus peel cell walls contain homogalacturonans homogenous with respect to molar mass, rhamnogalacturonan I and rhamnogalacturonan II," Carbohydrate Polymers, vol. 69, no. 3, pp. 426-435, 2007.

[14] A. J. Whitcombe, M. A. O’Neill, W. Steffan, P. Albersheim, and A. G. Darvill, "Structural characterizatrion of the pectic polysaccharide, rhamnogalacturonan-II," Carbohydrate Research, vol. 271, no. 1, pp. 15-29, 1995.

[15] S. Vidal, T. Doco, P. Williams et al., "Structural characterization of the pectic polysaccharide rhamnogalacturonan II: evidence for the backbone location of the aceric acidcontaining oligoglycosyl side chain," Carbohydrate Research, vol. 326, no. 4, pp. 277-294, 2000.

[16] A. G. Darvill, M. McNeil, and P. Albersheim, "Structure of plant cell walls. VIII. A new pectic polysaccharide," Plant Physiology, vol. 62, no. 3, pp. 418-422, 1978.

[17] I. Prabasari, F. Pettolino, M. L. Liao, and A. Bacic, "Pectic polysaccharides from mature orange (Citrus sinensis) fruit albedo cell walls: sequential extraction and chemical characterization," Carbohydrate Polymers, vol. 84, no. 1, pp. 484-494, 2011.

[18] B. L. Reuhs, J. Glenn, S. B. Stephens et al., "L-galactose replaces L-fucose in the pectic polysaccharide rhamnogalacturonan II synthesized by the L-fucose-deficient mur1 Arabidopsis mutant," Planta, vol. 219, no. 1, pp. 147-157, 2004.

[19] T. Doco, P. Williams, S. Vidal, and P. Pellerin, "Rhamnogalacturonan II, a dominant polysaccharide in juices produced by enzymic liquefaction of fruits and vegetables," Carbohydrate Research, vol. 297, no. 2, pp. 181-186, 1997.

[20] T. Shimokawa, T. Ishii, and T. Matsunaga, "Isolation and structural characterization of rhamnogalacturonan ll-borate complex from Pinus densiflora," Journal of Wood Science, vol. 45, no. 5, pp. 435-439, 1999.

[21] T. Ishii and S. Kaneko, "Oligosaccharides generated by partial hydrolysis of the borate- rhamnogalacturonan II complex from sugar beet," Phytochemistry, vol. 49, no. 5, pp. 11951202, 1998.

[22] T. Matsunaga, T. Ishii, S. Matsumoto et al., "Occurrence of the Primary Cell Wall Polysaccharide Rhamnogalacturonan II in Pteridophytes, Lycophytes, and Bryophytes. Implications for the Evolution of Vascular Plants," Plant Physiology, vol. 134, no. 1, pp. 339-351, 2004.

[23] R. I. Ortiz-Basurto, P. Williams, M. P. Belleville, and T. Doco, "Presence of rhamnogalacturonan II in the juices produced by enzymatic liquefaction of Agave pulquero stem (Agave mapisaga)," Carbohydrate Polymers, vol. 77, no. 4, pp. 870-875, 2009.

[24] P. Albersheim, A. G. Darvill, M. A. O’Neill, H. A. Schols, and A. G. J. Voragen, "An hypothesis: the same six polysaccharides are components of the primary cell walls of all higher plants," 
in Pectins and Pectinases, J. Visser and A. G. J. Voragen, Eds., pp. 47-55, Elsevier Science, Amsterdam, The Netherlands, 1996.

[25] J. R. Thomas, A. G. Darvill, and P. Albersheim, "Isolation and structural characterization of the pectic polysaccharide rhamnogalacturonan II from walls of suspension-cultured rice cells," Carbohydrate Research, vol. 185, no. 2, pp. 261-277, 1989.

[26] D. M. Dawson and L. D. Melton, "Two pectic polysaccharides from kiwifruit cell walls," Carbohydrate Polymers, vol. 15, no. 1, pp. 1-11, 1991.

[27] T. Ishii and T. Matsunaga, "Pectic polysaccharide rhamnogalacturonan II is covalently linked to homogalacturonan," Phytochemistry, vol. 57, no. 6, pp. 969-974, 2001.

[28] Y. Edashige and T. Ishii, "Rhamnogalacturonan II from cell walls of Cryptomeria japonica," Phytochemistry, vol. 49, no. 3, pp. 681-690, 1998.

[29] K. W. Talmadge, K. Keegstra, W. D. Bauer, and P. Albersheim, "Structure of plant cell walls. I. The macromolecular components of the walls of suspension-cultured sycamore cells with a detailed analysis of the pectic polysaccharides," Plant Physiology, vol. 51, no. 1, pp. 158-173, 1973.

[30] M. W. Spellman, M. McNeil, A. G. Darvill, P. Albersheim, and K. Henrick, "Isolation and characterization of 3-C-carboxy-5deoxy-l-xylose, a naturally occurring, branched-chain, acidic monosaccharide," Carbohydrate Research, vol. 122, no. 1, pp. 115-129, 1983.

[31] W. S. York, A. G. Darvill, M. McNeil, and P. Albersheim, “3deoxy-d-manno-2-octulosonic acid (KDO) is a component of rhamnogalacturonan II, a pectic polysaccharide in the primary cell walls of plants," Carbohydrate Research, vol. 138, no. C, pp. 109-126, 1985.

[32] T. T. Stevenson, A. G. Darvill, and P. Albersheim, "3-deoxyd-lyxo-2-heptulosaric acid, a component of the plant cellwall polysaccharide rhamnogalacturonan-II," Carbohydrate Research, vol. 179, no. C, pp. 269-288, 1988.

[33] G. Muralikrishna, P. V. Salimath, and R. N. Tharanathan, "Structural features of an arabinoxylan and a rhamnogalacturonan derived from linseed mucilage," Carbohydrate Research, vol. 161, no. 2, pp. 265-271, 1987.

[34] R. Naran, G. Chen, and N. C. Carpita, "Novel rhamnogalacturonan I and arabinoxylan polysaccharides of flax seed mucilage," Plant Physiology, vol. 148, no. 1, pp. 132-141, 2008.

[35] B. M. Yapo, "Rhamnogalacturonan-I: a structurally puzzling and functionally versatile polysaccharide from plant cell walls and mucilages," Polymer Reviews, vol. 51, no. 4, pp. 391-413, 2011.

[36] E. Zablackis, Huang Jing, B. Muller, A. G. Darvill, and P. Albersheim, "Characterization of the cell-wall polysaccharides of Arabidopsis thaliana leaves," Plant Physiology, vol. 107, no. 4, pp. 1129-1138, 1995.

[37] T. Doco, M. A. O'Neill, and P. Pellerin, "Determination of the neutral and acidic glycosyl-residue compositions of plant polysaccharides by GC-EI-MS analysis of the trimethylsilyl methyl glycoside derivatives," Carbohydrate Polymers, vol. 46, no. 3, pp. 249-259, 2001.

[38] G. R. Strasser and R. Amadò, "Pectic substances from red beet (Beta vulgaris L. var. conditiva). Part II. Structural characterisation of rhamnogalacturonan II," Carbohydrate Polymers, vol. 48, no. 3, pp. 263-269, 2002.

[39] E. Anderson, "The preparation of L-galactose from flaxseed mucilage," The Journal of the Biological Chemistry, vol. 100, pp. 249-253, 1933.
[40] B. L. Ridley, M. A. O’Neill, and D. Mohnen, "Pectins: structure, biosynthesis, and oligogalacturonide-related signaling," Phytochemistry, vol. 57, no. 6, pp. 929-967, 2001.

[41] P. Pellerin, T. Doco, S. Vidal, P. Williams, J. M. Brillouet, and M. A. O'Neill, "Structural characterization of red wine rhamnogalacturonan II," Carbohydrate Research, vol. 290, no. 2, pp. 183-197, 1996.

[42] M. Kobayashi, T. Matoh, and J. I. Azuma, "Two chains of rhamnogalacturonan II are cross-linked by borate-diol ester bonds in higher plant cell walls," Plant Physiology, vol. 110, no. 3, pp. 1017-1020, 1996.

[43] T. Ishii and T. Matsunaga, "Isolation and characterization of a boron-rhamnogalacturonan-II complex from cell walls of sugar beet pulp," Carbohydrate Research, vol. 284, no. 1, pp. $1-9,1996$.

[44] M. A. O’Neill, D. Warrenfeltz, K. Kates et al., "Rhamnogalacturonan-II, a pectic polysaccharide in the walls of growing plant cell, forms a dimer that is covalently cross-linked by a borate ester. In vitro conditions for the formation and hydrolysis of the dimer," Journal of Biological Chemistry, vol. 271, no. 37, pp. 22923-22930, 1996.

[45] T. Matoh, S. Kawaguchi, and M. Kobayashi, "Ubiquity of a borate-rhamnogalacturonan II complex in the cell walls of higher plants," Plant and Cell Physiology, vol. 37, no. 5, pp. 636-640, 1996.

[46] H. Hilz, P. Williams, T. Doco, H. A. Schols, and A. G. J. Voragen, "The pectic polysaccharide rhamnogalacturonan II is present as a dimer in pectic populations of bilberries and black currants in muro and in juice," Carbohydrate Polymers, vol. 65, no. 4, pp. 521-528, 2006.

[47] S. Aboughe-Angone, M. Bardor, E. Nguema-Ona et al., "Structural characterization of cell wall polysaccharides from two plant species endemic to central Africa, Fleurya aestuans and Phragmenthera capitata," Carbohydrate Polymers, vol. 75, no. 1, pp. 104-109, 2009.

[48] T. Ishii, T. Matsunaga, P. Pellerin, M. A. O’Neill, A. Darvill, and P. Albersheim, "The plant cell wall polysaccharide rhamnogalacturonan II self-assembles into a covalently cross-linked dimer," Journal of Biological Chemistry, vol. 274, no. 19, pp. 13098-13104, 1999.

[49] T. Ishii and H. Ono, "NMR spectroscopic analysis of the borate diol esters of methyl apiofuranosides," Carbohydrate Research, vol. 321, no. 3-4, pp. 257-260, 1999.

[50] M. Kobayashi, H. Nakagawa, T. Asaka, and T. Matoh, "Boraterhamnogalacturonan II bonding reinforced by $\mathrm{Ca}^{2+}$ retains pectic polysaccharides in higher-plant cell walls," Plant Physiology, vol. 119, no. 1, pp. 199-203, 1999.

[51] A. Fleischer, M. A. O'Neill, and R. Ehwald, “The pore size of non-graminaceous plant cell walls is rapidly decreased by borate ester cross-linking of the pectic polysaccharide rhamnogalacturonan II," Plant Physiology, vol. 121, no. 3, pp. 829-838, 1999.

[52] C. L. Jackson, T. M. Dreaden, L. K. Theobald et al., "Pectin induces apoptosis in human prostate cancer cells: correlation of apoptotic function with pectin structure," Glycobiology, vol. 17, no. 8, pp. 805-819, 2007.

[53] K. H. Caffall and D. Mohnen, "The structure, function, and biosynthesis of plant cell wall pectic polysaccharides," Carbohydrate Research, vol. 344, no. 14, pp. 1879-1900, 2009.

[54] A. G. J. Voragen, G. J. Coenen, R. P. Verhoef, and H. A. Schols, "Pectin, a versatile polysaccharide present in plant cell walls," Structural Chemistry, vol. 20, no. 2, pp. 263-275, 2009.

[55] M. Séveno, E. Séveno-Carpentier, A. Voxeur et al., "Characterization of a putative 3-deoxy-D-manno-2-octulosonic acid 
(Kdo) transferase gene from Arabidopsis thaliana," Glycobiology, vol. 20, no. 5, Article ID cwq011, pp. 617-628, 2010.

[56] A. Voxeur, L. Gilbert, C. Rihouey et al., "Silencing of the GDPD-mannose 3,5-epimerase affects the structure and crosslinking of the pectic polysaccharide rhamnogalacturonan II and plant growth in tomato," Journal of Biological Chemistry, vol. 286, no. 10, pp. 8014-8020, 2011.

[57] J. N. Glushka, M. Terrell, W. S. York et al., "Primary structure of the 2-O-methyl- $\alpha$-L-fucose-containing side chain of the pectic polysaccharide, rhamnogalacturonan II," Carbohydrate Research, vol. 338, no. 4, pp. 341-352, 2003.

[58] M. N. V. Williams, G. Freshour, A. G. Darvill, P. Albersheim, and M. G. Hahn, "An antibody Fab selected from a recombinant phage display library detects deesterified pectic polysaccharide rhamnogalacturonan II in plant cells," Plant Cell, vol. 8, no. 4, pp. 673-685, 1996.

[59] W. G. T. Willats, L. Mccartney, W. Mackie, and J. P. Knox, "Pectin: cell biology and prospects for functional analysis," Plant Molecular Biology, vol. 47, no. 1-2, pp. 9-27, 2001.

[60] J. Harholt, A. Suttangkakul, and H. V. Scheller, "Biosynthesis of pectin," Plant Physiology, vol. 153, no. 2, pp. 384-395, 2010.

[61] J. P. Vincken, H. A. Schols, R. J. F. J. Oomen et al., "If homogalacturonan were a side chain of rhamnogalacturonan I. Implications for cell wall architecture," Plant Physiology, vol. 132, no. 4, pp. 1781-1789, 2003.

[62] C. Somerville, S. Bauer, G. Brininstool et al., "Toward a systems approach to understanding plant cell walls," Science, vol. 306, no. 5705, pp. 2206-2211, 2004.

[63] B. M. Yapo, "Pectic substances: from simple pectic polysaccharides to complex pectins-a new hypothetical model," Carbohydrate Polymers, vol. 86, no. 2, pp. 373-385, 2011.

[64] F. Delmas, M. Séveno, J. G. B. Northey et al., "The synthesis of the rhamnogalacturonan II component 3-deoxy-D-manno2- octulosonic acid (Kdo) is required for pollen tube growth and elongation," Journal of Experimental Botany, vol. 59, no. 10, pp. 2639-2647, 2008.

[65] P. Pellerin and M. A. O’Neill, “The interaction of the pectic polysaccharide Rhamnogalacturonan II with heavy metals and lanthanides in wines and fruit juices," Analusis, vol. 26, no. 6, pp. M32-M36, 1998.

[66] M. Tahiri, P. Pellerin, J. C. Tressol et al., "The rhamnogalacturonan-II dimer decreases intestinal absorption and tissue accumulation of lead in rats," Journal of Nutrition, vol. 130, no. 2, pp. 249-253, 2000.

[67] M. Tahiri, J. Tressol, T. Doco, Y. Rayssiguier, and C. Coudray, "Chronic oral administration of rhamnogalacturonan-II dimer, a pectic polysaccharide, failed to accelerate body lead detoxification after chronic lead exposure in rats," British Journal of Nutrition, vol. 87, no. 1, pp. 47-54, 2002.

[68] H. Yamada, "Pectic polysaccharides from Chinese herbs: structure and biological activity," Carbohydrate Polymers, vol. 25, no. 4, pp. 269-276, 1994.

[69] K. S. Shin, H. Kiyohara, T. Matsumoto, and H. Yamada, "Rhamnogalacturonan II dimers cross-linked by borate diesters from the leaves of Panax ginseng C.A. Meyer are responsible for expression of their IL-6 production enhancing activities," Carbohydrate Research, vol. 307, no. 1-2, pp. 97106, 1998.

[70] T. T. Stevenson, A. G. Darvill, and P. Albersheim, "Structural features of the plant cell-wall polysaccharide rhamnogalacturonan-II," Carbohydrate Research, vol. 182, no. 2, pp. 207-226, 1988. 


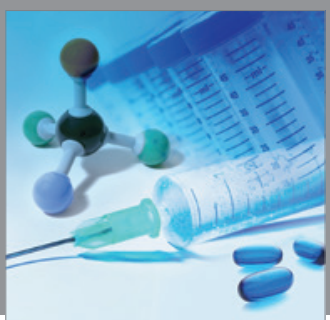

International Journal of

Medicinal Chemistry

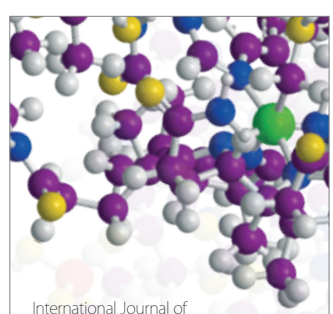

Carbohydrate Chemistry

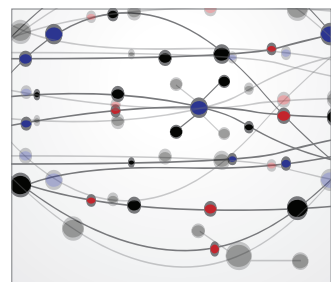

The Scientific World Journal
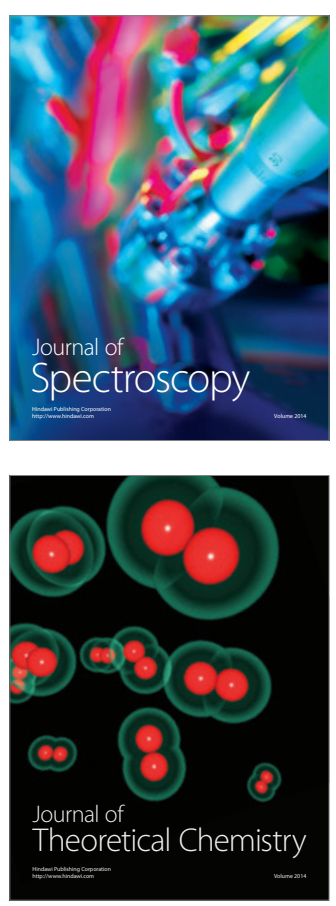
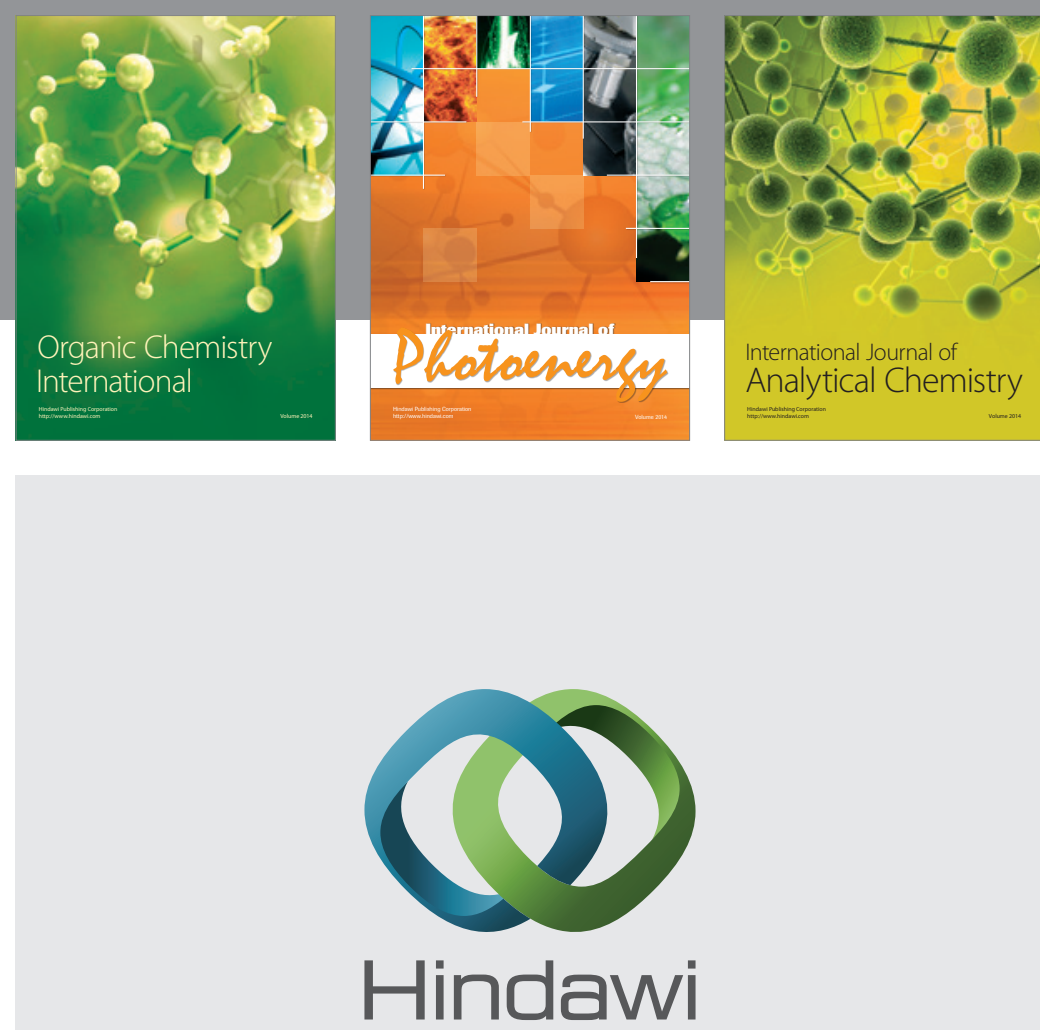

Submit your manuscripts at

http://www.hindawi.com
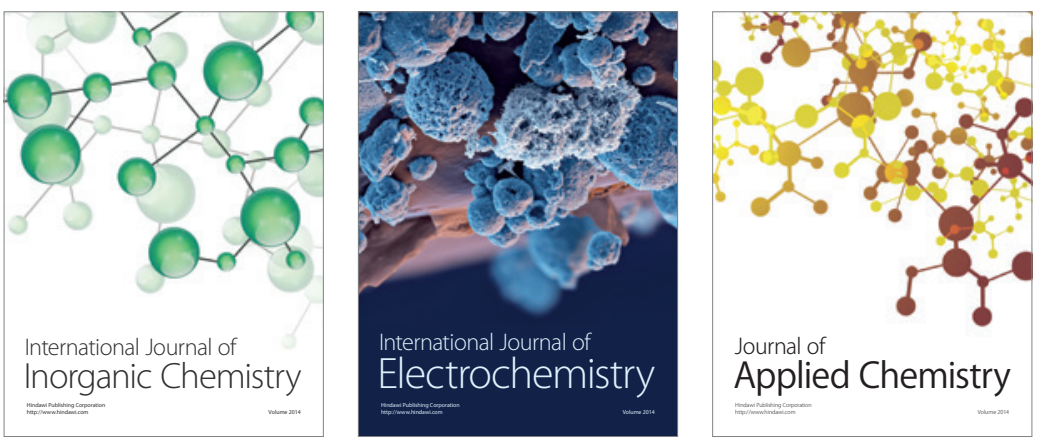

Journal of

Applied Chemistry
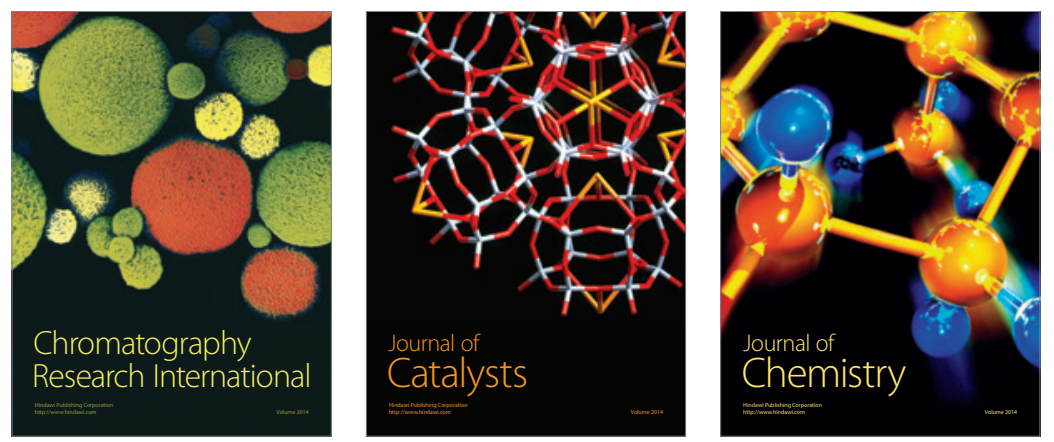
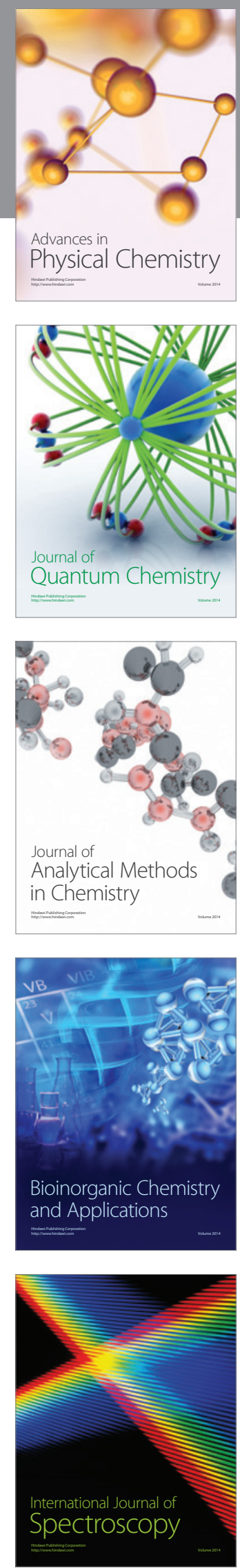